\title{
Ka-Band Propagation Measurements: An Opportunity with the Advanced Communications Technology Satellite (ACTS)
}

\author{
ROBERT BAUER
}

\author{
Invited Paper
}

The Advanced Communications Technology Satellite (ACTS) was conceived at the National Aeronautics and Space Administration (NASA) as a follow-on program to its long history in satellite communications projects that have reduced the risk of developing new technologies that fall outside the sponsorship capability of the private sector. To counter the foreign challenge that developed in the late 1970's to the once insuperable U.S. lead in this field, ACTS was developed to maintain the U.S. preeminence. Launched in September 1993 from the space shuttle, key technologies on ACTS include a multibeam antenna, a baseband processor, a 900- $\mathrm{MHz}$ wideband microwave switch matrix, adaptive rain fade compensation techniques, and the use of Ka-band frequencies. Since this is the United States' first effort in using Ka-band for satellite communications, beacons are incorporated on the satellite, which provide an opportunity for propagation measurements. NASA is sponsoring a network of propagation experimenters using these beacons and receive-only terminals identical in design. This paper provides some history that leads to the eventual development of ACTS. Also, a system overview of the spacecraft is provided for those less familiar with it.

Keywords-ACTS, beacons, Ka-band, propagation measurements, 30/20 GHz program.

\section{INTRODUCTION}

There generally are few opportunities to perform propagation measurements from space-based platforms. The National Aeronautics and Space Administration (NASA) is pleased that as one way to improve radio science and propagation studies, the beacons on the Advanced Communications Technology Satellite (ACTS) could be used as a source for such purposes and that it could sponsor a propagation measurement program. The history of the ACTS program goes back many years. The nostalgia of the very early years in satellite communications is always interesting to review to see how advances in this area

Manuscript received August 25, 1996; revised December 1, 1996.

The author is with the NASA Lewis Research Center, Columbus, OH 44135 USA.

Publisher Item Identifier S 0018-9219(97)04653-7. of communications have evolved into a multibillion-dollar industry today.

The relevance of ACTS and the government's involvement in developing another experimental communication satellite were questioned, as evidenced by the "onagain/off-again" status of the project's budget throughout the 1980's. However, considering that 14 applications for use of the Ka-band for various geostationary systems were received by the Federal Communications Commission in September 1995, the success of ACTS in demonstrating the use of Ka-band as a feasible band for commercial operations was clearly implied.

While the majority of the papers in this special issue are technical papers reporting significant results from direct ACTS measurements, this paper's emphasis is on offering an introduction to the issue and providing background on the ACTS system and propagation program. Therefore, this paper begins with a brief history of the satellite programs that led to the development of ACTS, including the turbulent budgetary years that threatened the existence of the program. An overview of the ACTS system is given, followed by a discussion of the subsystem providing the signal source for long-term propagation studies-the ACTS beacons. Last, the ACTS propagation program is discussed.

\section{ACTS PROJECT BACKGROUND}

\section{A. NASA's Communication Satellite History}

NASA has been involved with the development of the communications satellite since the early 1960's, from the early passive reflectors to today's digital signal repeaters. Early developments, when little knowledge of operating communications systems in the space environment was available, were truly experimental. As the technology matured, private industry began developing and operating its own satellites. NASA was always associated with the industry because it provided the space launch operations and 
improvements in the technology that were still expensive and too risky for any single company to pursue.

The earliest systems included the Echo I and II, which were launched in 1960 and 1964, respectively. Although passive systems in low earth orbit, they were basically giant balloons of radio reflective material and confirmed basic communication satellite principals. Two-way voice links of good quality were set up between Bell Laboratories in Holmdel, NJ and the NASA station at Goldstone, CA. Some transmissions from the United States were received in England. Echo demonstrated satellite tracking and ground station technology that would be used in later active systems.

Following Echo was the Relay series of satellites (I launched in 1962, and II launched in 1964). These active satellite systems operated at a medium altitude orbit that took them through the earth's inner radiation belts, which allowed the effects of these belts on satellite electronics to be studied. Each of the redundant transponders had one $25-\mathrm{MHz}$ wideband channel (capable of carrying 300 voice circuits or one TV signal) and two 2-MHz narrow-band (12 two-way voice) channels [1].

Telstar was a two-satellite program using active repeaters and like Relay, it operated in a medium altitude orbit. Built by AT\&T, the Telstar satellites were launched by NASA: Telstar I in 1962 and Telstar II in 1963. Both were successful.

The synchronous communications, or Syncom, series was intended to demonstrate the technology for synchronousorbit active repeater satellites for global communication. Syncom I was launched in 1963. It was placed in a nearly synchronous orbit but contact with the satellite was lost. Syncom II was launched in 1963 but ended up in an inclined orbit. Syncom III, launched in 1964, was the world's first geostationary satellite. Syncom II and III were eventually turned over to the Department of Defense in 1965 and were turned off in 1969 [2].

The Advanced Technology Satellites were conceived of as follow-ons to the successful experimental communications satellites of the early 1960's with the addition of other technology demonstrations, such as weather observation and investigation of the space environment. Six spacecraft were eventually flown between 1966 and 1974. ATS-3 still remains active after 26 years of operations. ATS-6 demonstrated the technology used in the current tracking and data relay satellites primarily for transmitting data from various low earth orbiting systems to earth (including the shuttle).

The Communications Technology Satellite (CTS) was launched in 1976 as a joint program between the United States and Canada. Its high-power Ku-band transmitter proved the technology for the current very small aperture terminal (VSAT) and direct broadcast television market. It operated until 1979.

After the CTS program, NASA's plans for future communication satellites were reduced, mostly due to the success of the satellite industry. The founding of the Communications Satellite Corporation and the International Satellite
Consortium demonstrated that satellite communications had become a mature technology and blossoming industry. By October 1980, eight U.S. domestic satellites and four Canadian satellites were serving the North American continent.

From a 1973 peak funding of about $\$ 170$ million, NASA's communication program fell to about $\$ 20$ million by 1975 , since it was argued that industry could support its own R\&D. Also, while the U.S. satellite communications R\&D programs slowed during 1973-1979, the Japanese and European efforts accelerated. With the same foresight as was applied with earlier satellite development, however, NASA forecasts showed that the increased usage of satellites would result in eventual orbit saturation. Both Cband $(6 / 4 \mathrm{GHz})$ and $\mathrm{Ku}$-band $(14 / 12 \mathrm{GHz})$ orbit allocations over the United States were forecast to be fully utilized by the late 1990's. Some other technology breakthrough would be needed to satisfy the ever increasing use of satellites. It had become clear that without appropriate government support, the U.S. satellite lead would be lost, following the unfortunate precedent established in the consumer electronics industry.

\section{B. 30/20-GHz Program}

In 1978, Congress responded to industry's urging that NASA reinstitute a vigorous satellite communications program, which resulted in the " $30 / 20 \mathrm{GHz}$ Communications Program." To help NASA provide the most effective program, an industry task group was formed in 1979, which included the leading U.S. firms involved in communications satellite development and operations to define the type of system that would best meet the users' needs and requirements. The group was called the Carrier Working Group and helped formulate system requirements, develop experiment plans, critique design concepts, and provide overall guidance and advice regarding the next generation of communication satellites. The technologies developed would be those that were too costly or risky for any single company to develop on its own. The industry participants were American Satellite, AT\&T Long Lines, Bell Telephone Labs, Comsat General, GTE Satellite Communications, Hughes Communications Services, IT\&T, RCA American Communications, Satellite Business Systems, and Western Union [3].

\section{ACTS PROJECT}

\section{A. Early Years}

The $30 / 20-\mathrm{GHz}$ program eventually was restructured and renamed the Advanced Communications Technology Satellite Program in 1983 to continue the line of NASA experimental communications satellites. ACTS had a long and tortuous existence through the 1980's as Congress and the White House debated the philosophy of having NASA develop technology for the U.S. satellite communications industry [4]. Three times during the design and development period (fiscal years 1985, 1987, and 1988), it was canceled by the President's Office of Management and 
Budget (OMB) only to have Congress reinstate funding for ACTS. Even in 1989, the OMB did not request funding. Congress again funded the program [5]. As a result of this, along with development delays and shuttle-related slips, the ACTS launch was delayed five years while project costs grew from approximately $\$ 350$ to $\$ 500$ million. (Because of cost overruns, the program was capped in 1988 at $\$ 499$ million by Congress.)

The spacecraft was built by Lockheed Martin AstroSpace in East Windsor, NJ. The contract to design, launch, and operate the spacecraft was awarded in August 1984 to what was then RCA Astro-Space (now Lockheed Martin Astro Space). ${ }^{1}$ The spacecraft's baseband processor, the key specially designed integrated circuit of the digital communication payload, was designed and built by Motorola as an RCA subcontractor.

Comsat Laboratories in Clarksburg, MD, built and currently operates the ACTS Ka-band Master Control Station (MCS), which is part of the NASA Ground Station at the Lewis Research Center in Cleveland, OH. The MCS controls the communications payload and is used for all Ka-band control communications with the spacecraft. A terrestrial link connects it to the Astro Space facility so that spacecraft control files generated at Astro Space can be uplinked from NASA Lewis.

Despite the program delays and three scrubbed launch attempts, ACTS was successfully orbited on September 12, 1993. It arrived at its geosynchronous station of $100^{\circ} \mathrm{W}$ longitude 16 days later and continues (as of this writing) operating nearly flawlessly. The unique feature of ACTS is that it is a "switchboard in the sky," that is, it has the operational likeness of an AT\&T \#4 electronic switching system digital central office switch. The ACTS communication payload incorporates onboard switching and antennas providing hopped, fixed, and steerable spot-beams that allow routing of signals to take place on the spacecraft [6]. The Ka-band frequencies used on ACTS, 30-GHz uplink and 20-GHz downlink, are new capabilities for U.S. communications satellites (the Japanese, however, were first to launch a $30 / 20-\mathrm{GHz}$ satellite). The use of these high frequencies makes wide-bandwidth channels $(900 \mathrm{MHz})$ available.

\section{B. System Overview}

The ACTS program's objectives are to develop the highrisk, high-cost, advanced communications technologies usable in multiple frequency bands that would be applicable to a wide range of future communications systems for U.S. industry, NASA, and other domestic government agencies. The technologies are to enable the growth in capacity and effective use of the frequency spectrum and enable U.S.

\footnotetext{
${ }^{1}$ Later, General Electric bought RCA and renamed the company GE Astro-Space. Again, Astro-Space was sold and purchased by Martin Marietta in April 1993 and was renamed Martin Marietta Astro Space. The consolidation of the aerospace industry that ensued in the difficult economic times following the end of the cold war resulted in Martin Marietta's merging with Lockheed. The company, known today as Lockheed Martin, has plans to consolidate its East Windsor operations in Sunnyvale, CA.
}

industry to maintain its competitiveness in the international communications satellite market. The approach to this is to develop and flight test the key technology areas identified as spot beams, onboard digital communications (baseband processing), use of Ka-band, and very wide bandwidth transponders (microwave switch matrix or MSM).

The most significant technologies being validated as part of the ACTS program are as follows.

1) A multibeam antenna that provides a rapidly reconfigurable pattern of 48 narrow high-gain, hopping spot beams and three fixed spot beams [7]. A separate transmit and receive reflector (2.2- and 3.3-m diameter, respectively) are in an offset Cassegrain configuration and use a fixed network of horns in beamforming networks to develop the individual beams. A station-keeping accuracy of $0.05^{\circ}$ and antennapointing requirement of $0.025^{\circ}$ are being met or exceeded in order to maintain the accurate pointing of these thin beams.

2) A baseband processor that is a high-speed digital processor on board the satellite that demodulates, stores, and regenerates the baseband signals received before being retransmitted. It efficiently uses transponder capacity by routing individual, $64 \mathrm{~kb} / \mathrm{s}$, circuit-switched messages and provides single-hop interconnectivity in a full mesh network [8], [9].

3) An MSM, which is a dynamically reconfigurable intermediate frequency switch capable of routing highvolume point-to-point and point-to-multipoint traffic over channels that have a $900-\mathrm{MHz}$ bandwidth.

4) The development of Ka-band components, which were part of the flight and ground segment hardware at 20 and $30 \mathrm{GHz}$.

5) VSAT's using antennas with diameters of $1.2 \mathrm{~m}$ to handle high transmit-and-receive throughput rates (1.544 Mb/s) [10].

6) Network control techniques by using advanced algorithms to provide flexible and efficient demandassigned multiple accessed communications in a mesh network [11].

7) Adaptive signal fade compensation using techniques such as forward error correction and burst rate reduction, which are activated on an "as-needed" basis independently on the uplink and downlink.

The advanced technologies developed for ACTS are usable in frequency bands other than the 30/20-GHz Ka-band and can support a wide range of future communications systems. The advantages realized by these technologies are the basis for providing low-cost satellite communications, especially to regions where terrestrial service is too costly or completely impractical [12]. Also, the technologies provided by ACTS are necessary for developing tomorrow's networks that will use both satellite and terrestrial services seamlessly interconnected. Examples of the satellite portion of these future networks include: 1) VSAT digital networks 
providing on-demand, full mesh connectivity at $1.544 \mathrm{Mb} / \mathrm{s}$ in a single satellite hop; 2) high data rate point-to-point or point-to-multipoint networks on the order of a gigabit per second using an MSM; 3) low data rate (kilobits per second) personal communications system networks using ultra-small aperture terminals; and 4) mobile communications networks using the less congested Ka-frequency band for higher data rate services than currently possible at L-band.

The ACTS system is available for experiments by industry, universities, and other government agencies as well as for demonstrations that evaluate new service applications. An active experiments program includes approximately 100 experimenters that are using or will be using the system [13]. Over 70 (as of this writing) short-duration demonstrations have also been performed covering a wide variety of applications to a diverse range of audiences. The spacecraft's projected operational lifetime is through July 1998 based on station-keeping fuel projections made in May 1996. Operating the system in an inclined orbit by eliminating the last north-south station-keeping maneuver has the potential of extending the operational life by 30 months and is being investigated by NASA.

\section{ACTS BEACONS}

With the background and overview of the ACTS system completed, the remainder of this paper focuses on the portion of the system that provides the opportunity for propagation Ka-band measurements - that is, the beacons.

\section{A. Description}

Since ACTS is the United States' only experimental system operating at Ka-band frequencies, characterization of the frequency band for the increased rain fade experienced at these frequencies was needed. Two beacons are installed on ACTS: one in the downlink frequency band at 20.185 $\mathrm{GHz}$ (20.2 GHz for short) and the other in the uplink frequency band at $27.505 \mathrm{GHz}(27.5 \mathrm{GHz}$ for short), which provide signal sources to make continuous measurements for propagation research. The beacons, however, were not added just for propagation research, and so a description of their mission operations functions is provided first.

The 20.2-GHz beacon is modulated with telemetry transmitted from the spacecraft to the master control station. The 27.5-GHz beacon is unmodulated and can be used by the ground stations for predicting uplink signal fades. The beacon antennas provide broad coverage to the continental United States (Fig. 1). Since the 20.2-GHz beacon carries telemetry, it was critical to have a spare, and so one was included that operates at $20.195 \mathrm{GHz}$. It has only occasionally been activated since the completion of initial on-orbit checkout. The $27.5-\mathrm{GHz}$ beacon also has a redundant backup at the same frequency and polarization. The two beacons are derived from independent frequency oscillators, and therefore are not coherent to one another. This was done for reasons concerning redundancy and system weight and cost.
Two beacon reflectors are situated on the face panel of the spacecraft, as shown in Fig. 2, in an elliptical offset fashion. More detailed diagrams of the beacons are presented in Fig. 3. The 20.2-GHz beacon pattern is formed from a single radiating horn and the $27.5-\mathrm{GHz}$ beacon pattern is formed by two horns. The $20.2-\mathrm{GHz}$ reflector is the smaller of the two and measures approximately 11 by 6.5 in while the $27.5-\mathrm{GHz}$ reflector is approximately 13 by $7.5 \mathrm{in}$.

The two $20.2-\mathrm{GHz}$ beacon signals are cross polarized. Only one of two signals is used at a time. The primary $20.185-\mathrm{GHz}$ beacon is vertically polarized while the redundant $20.195-\mathrm{GHz}$ beacon is horizontally polarized. The $27.5-\mathrm{GHz}$ beacon is vertically polarized. The reflector that forms the $27.5-\mathrm{GHz}$ beacon pattern transmits the continuous wave beacon and receives uplinked commands at $30 \mathrm{GHz}$ [see Fig. 3(b)]. These transmitted and received signals are also cross polarized. Table 1 provides operating characteristics of the beacons.

\section{B. Command, Ranging, and Telemetry Functions}

The beacons are part of the command, ranging, and telemetry (CR\&T) subsystem, which can be divided into three functional areas: two areas that operate at radio frequencies (RF) and a third that operates at digital baseband. The two RF systems comprise $\mathrm{C}$ - and Ka-band receivers and transmitters. The C-band commands control spacecraft bus functions and were used during launch and throughout the transfer and drift orbit phase while the satellite was being placed into geosynchronous orbit. An omnidirectional antenna is used for C-band communications. Daily operations use the Ka-band CR\&T link. Should Ka-band communications become disrupted (e.g., spacecraft is inadvertently mispointed), C-band communications would be reactivated until Ka-band communications were securely restored.

The digital baseband system performs the CR\&T processing, such as processing the low- and high-rate commands received by the satellite. The low-rate commands control positioning and attitude of the satellite. The high-rate commands control the normal operations of the communications payload and are transmitted over the Ka-band link only.

The 20.2-GHz downlinked telemetry data are compiled onboard the spacecraft by a Redundant Telemetry Module (RTM). The RTM generates five subcarriers at 14.5, 19, 27.8, 32, and $64 \mathrm{kHz}$. These subcarriers are used for analog dwell telemetry, coarse ranging, fine ranging, placeholder tone, and digital pulse-code modulated telemetry/command verification, respectively [14].

In the normal mode of operation, the $20.2-\mathrm{GHz}$ beacon carrier signal is modulated by the $32 \mathrm{kHz}$ and the $64-$ $\mathrm{kHz}$ subcarriers. The $32-\mathrm{kHz}$ subcarrier is unmodulated. It is used as a placeholder to maintain the power of the modulated carrier when ranging is not being done. The 64-kHz subcarrier carries $1000 \mathrm{~b} / \mathrm{s}$ telemetry from the spacecraft bus and the communications payload and also carries command verification data [15]. Ranging is done simultaneously with the $64-\mathrm{kHz}$ telemetry transmission by substituting ranging tones for the $32-\mathrm{kHz}$ subcarrier. 


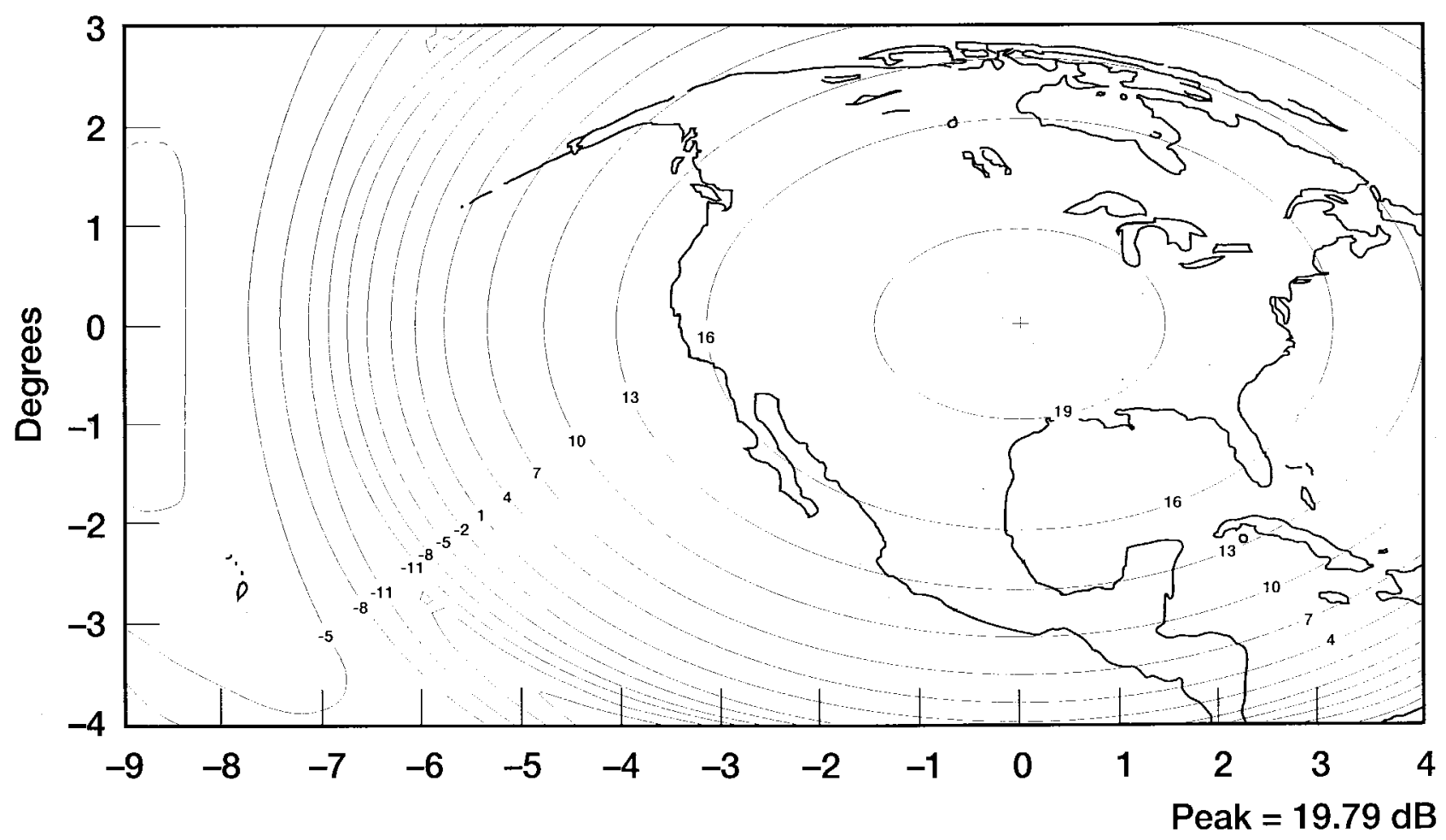

Degrees

(a)

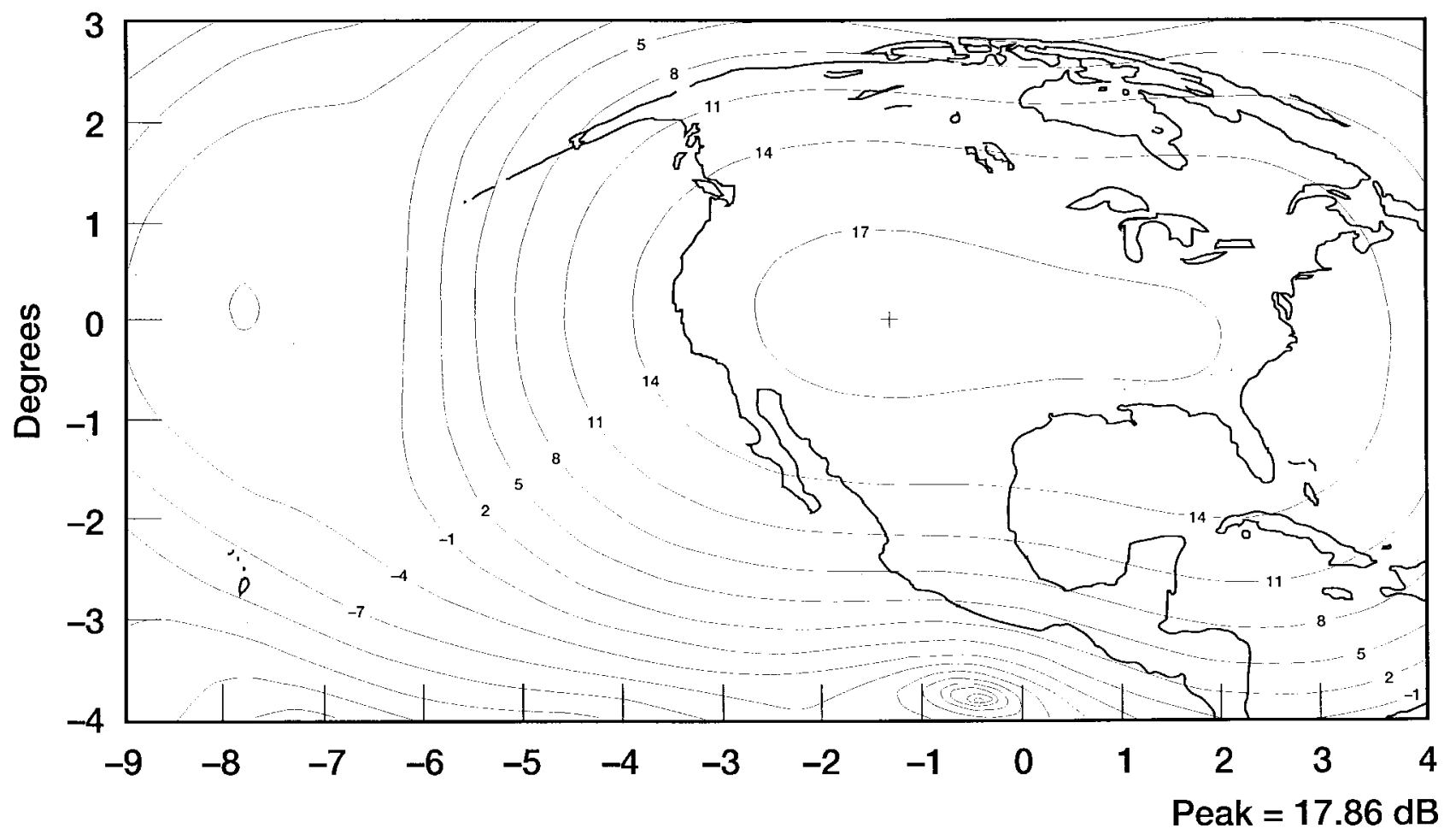

Degrees

(b)

Fig. 1. ACTS propagation beacon patterns. (a) $20.185 \mathrm{GHz}$. (b) $27.505 \mathrm{GHz}$. 


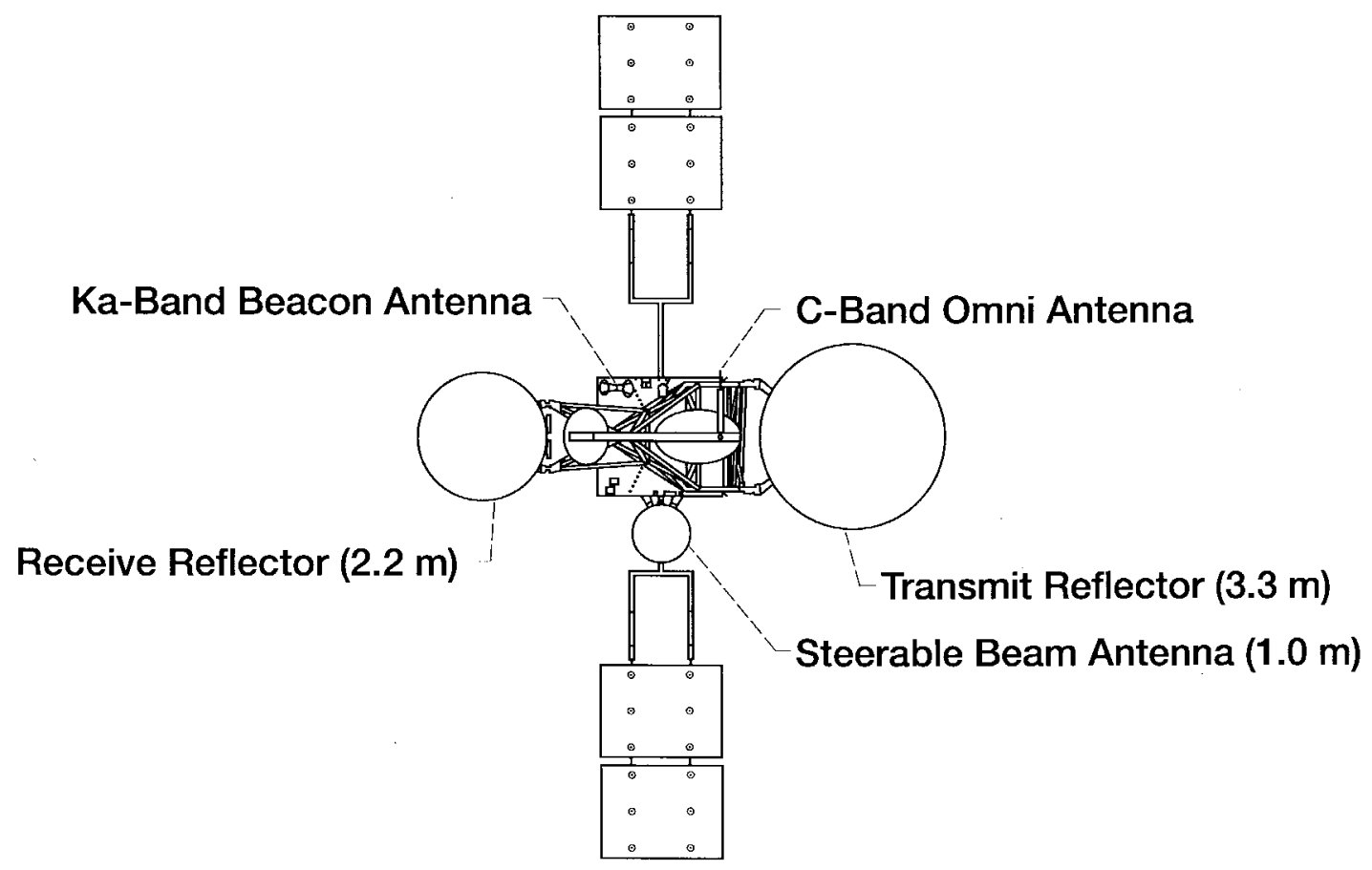

Fig. 2. Location of ACTS beacon antenna on the spacecraft.
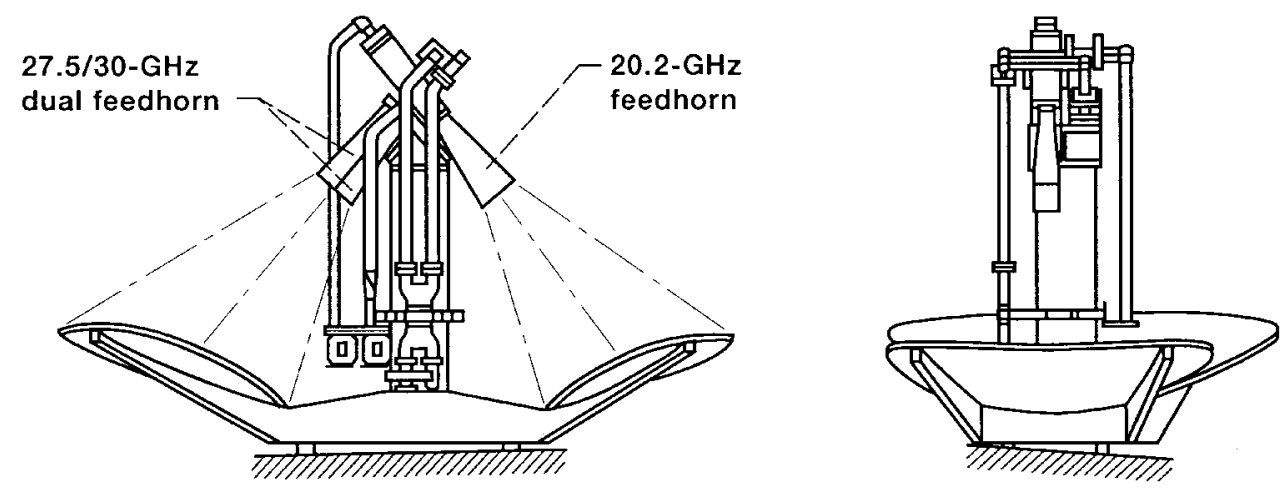

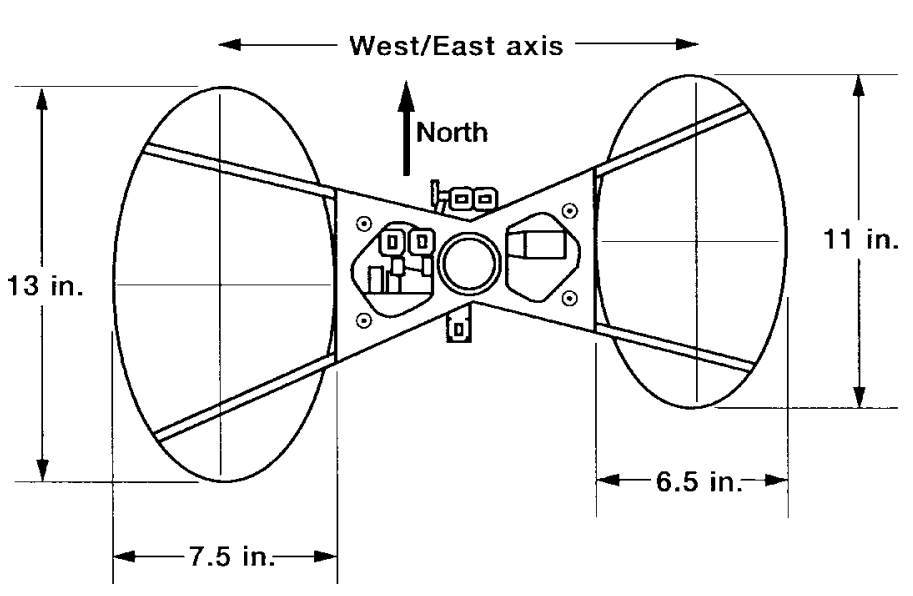

(a)

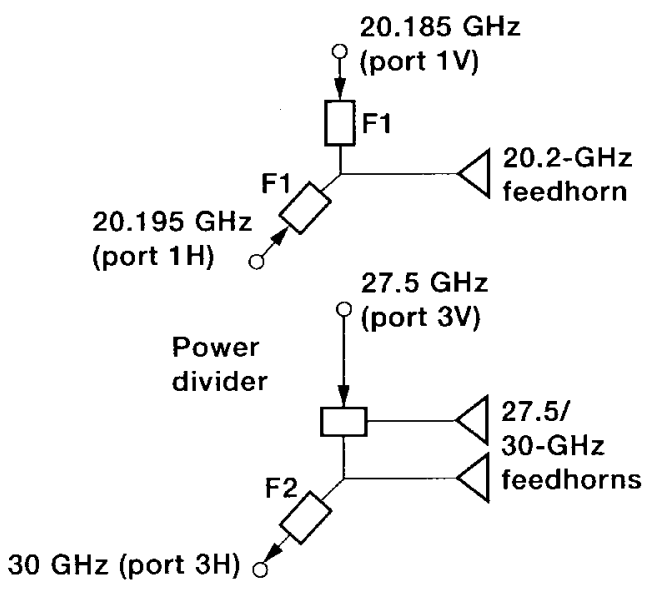

(b)

Fig. 3. Detailed diagrams of the beacon antenna. (a) Layout of antenna. (b) Block diagram of feed assembly. 


\section{NASA Propagation Terminal \\ Tampa, Florida}

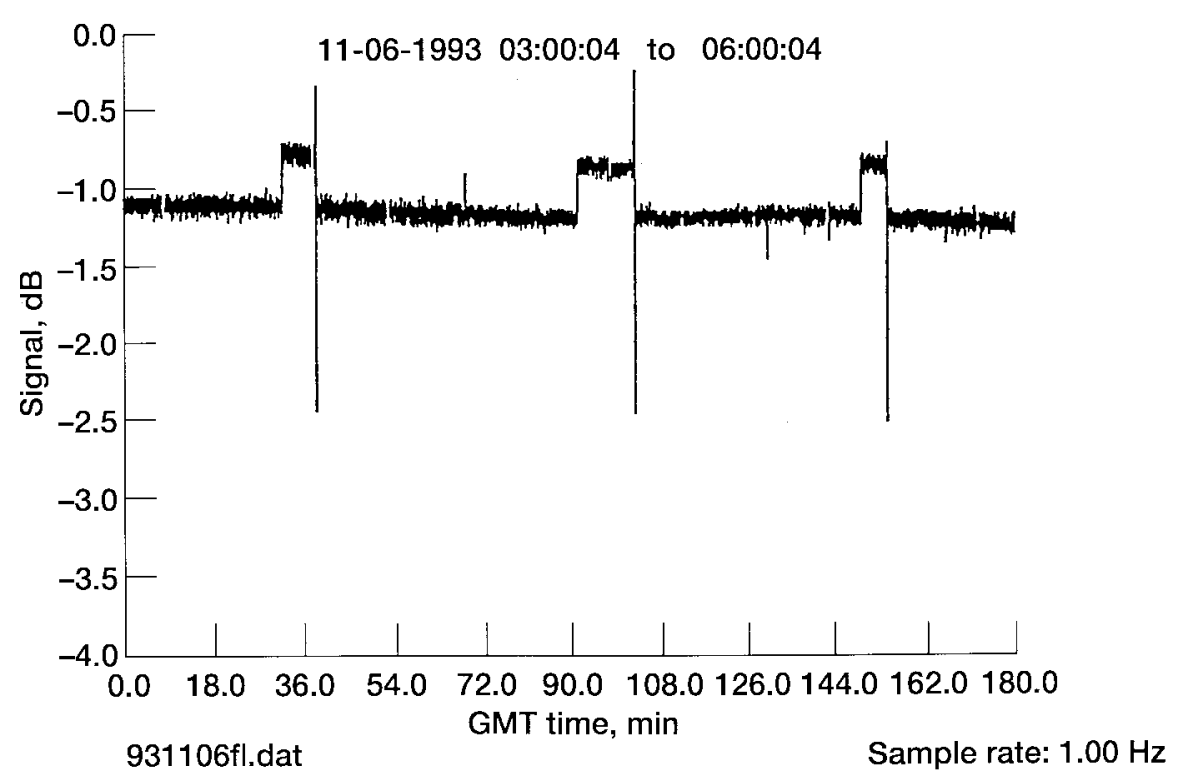

Fig. 4. Ranging pulses on a $20.2-\mathrm{GHz}$ beacon signal.

Table 1 Characteristics of the Beacon Signals

\begin{tabular}{|c|c|c|}
\hline Characteristic & $\begin{array}{c}\text { Uplink Fade Beacon; } \\
27.5 \mathrm{GHz}, \\
\text { unmodulated carrier }\end{array}$ & $\begin{array}{c}\text { Downlink Telemetry } \\
\text { Beacons; } 20.2 \text { GHz, } \\
\text { modulated carrier }\end{array}$ \\
\hline $\begin{array}{l}\text { Carrier Frequency at beginning } \\
\text { of life, } \mathrm{GHz} \pm \mathrm{MHz}\end{array}$ & $27.505 \pm 0.5$ & $\begin{array}{l}20.185 \pm 0.3(\mathrm{~V}-\mathrm{Pol}) \\
20.195 \pm 0.3(\mathrm{H}-\mathrm{Pol})\end{array}$ \\
\hline $\begin{array}{l}\text { Measured beacon frequencies } \\
\text { from box and subsystem testing } \\
\text { of the flight hardware, } \mathrm{GHz}\end{array}$ & $\begin{array}{r}\text { Uplink Fadc Beacon } \\
\# 1-27.504973 \\
\text { Uplink Fade Beacon } \\
\# 2-27.505028\end{array}$ & $\begin{array}{l}\text { Primary - } 20.185013 \\
\text { Back-up - } 20.194897\end{array}$ \\
\hline $\begin{array}{l}\text { Frequency Stability, ppm: At } \\
\text { any one temperature over }-10 \text { to } \\
42^{\circ} \mathrm{C}\end{array}$ & \multicolumn{2}{|c|}{$\begin{array}{l} \pm 10 \text { over } 2 \text { years } \\
4 \text { pk. to pk. in } 24 \mathrm{hr} .\end{array}$} \\
\hline Operating Temperature, ${ }^{\circ} \mathrm{C}$ & -5 to 36 & -5 to 39 \\
\hline $\begin{array}{l}\text { Minimum RF Power at end of } \\
\text { life, } \mathrm{dBm}\end{array}$ & 19.0 & 22.5 \\
\hline $\begin{array}{l}\text { Maximum Output Power } \\
\text { Stability, dB }\end{array}$ & $\begin{array}{l} \pm 1 \text { over } 24 \mathrm{hr} \\
\pm 2 \text { over } 2 \mathrm{yr} \text {. }\end{array}$ & $\begin{array}{l} \pm 0.5 \text { over } 24 \mathrm{hr} \text {. } \\
\pm 1.5 \text { over } 2 \mathrm{yr} \text {. }\end{array}$ \\
\hline $\begin{array}{l}\text { Minimum Effective Isotropic } \\
\text { Radiated Power for fade } \\
\text { measurements, dBW }\end{array}$ & 15.5 & 17.5 \\
\hline
\end{tabular}

Fade measurements at the downlink frequency (20.2 $\mathrm{GHz}$ ) are practically unaffected by the beacon modulation in the operational telemetry modes or by the contents of the telemetry data. The modulation levels have been set to provide nearly constant power in the carrier central line. However, ranging operations caused early concern with the propagation beacon measurements because the carrier-level increases of about $0.4 \mathrm{~dB}$ during these short periods were unexpected. A sample frequency response of the $20-\mathrm{GHz}$ beacon signal with a ranging pulse is shown in Fig. 4. Ranging was originally conducted daily every hour for a period of approximately $5 \mathrm{~min}$. Now that operations have matured, it is done about every four hours. For several hours after a station-keeping maneuver, it is done hourly. During ranging, the $32-\mathrm{kHz}$ subcarrier is replaced with the $27.8-\mathrm{kHz}$ ranging tone. An amplitude spike occurs when ranging is being completed depending on the precision of the spacecraft operators executing ranging commands. Sometimes there may be a few seconds when only the $64-\mathrm{kHz}$ carrier is present, thereby causing a spike. The ACTS propagation terminals' data-processing software was modified to remove the ranging pulses from the processed data.

Fade measurements at the uplink frequency $(27.5 \mathrm{GHz})$ are undisturbed by modulation, but they are available only for the vertical polarization. The redundant $27.5-\mathrm{GHz}$ beacon was activated on November 16, 1993, to replace the original signal that had been 4-dB low since turn-on. The frequencies of both beacons continue to be very stable, measured as $<1800 \mathrm{~Hz}$ diurnal variation and no more than $-7400 \mathrm{~Hz}$ yearly drift. Daily variations in received signal level of up to $1 \mathrm{~dB}$ have been reported [16].

\section{ACTS PROPAGATION STUdIES OPPORTUNITY}

\section{A. ACTS Propagation Experiments Implementation Program}

Since a major development on ACTS was the use of the Ka-frequency band, characterization of the band's greater fading due to atmospheric propagation effects using the beacons onboard the satellite was seen as an important result that the project should provide. To ensure that a careful propagation studies campaign would be performed with ACTS, NASA headquarters provided funding to develop and operate an ACTS-focused propagation studies program. An excellent description of the program and each of the 
Table 2 ACTS Class I Propagation Experiments

\begin{tabular}{|c|c|c|c|c|c|c|}
\hline$\#$ & $\begin{array}{l}\text { Principal } \\
\text { Investigator }\end{array}$ & $\begin{array}{l}\text { Co- } \\
\text { Investigator }\end{array}$ & Experiment Title & $\begin{array}{l}\text { Terminal } \\
\text { Location }\end{array}$ & $\begin{array}{l}\text { Path El., } \\
\text { degrees }\end{array}$ & $\begin{array}{l}\text { ITU } \\
\text { Rain } \\
\text { Zone }\end{array}$ \\
\hline 1 & $\begin{array}{l}\text { University of } \\
\text { British Columbia }\end{array}$ & $\begin{array}{l}\text { Communications } \\
\text { Research Centre }\end{array}$ & $\begin{array}{l}\text { ACTS Ka-Band Propagation } \\
\text { Measurements in a West } \\
\text { Coast Maritime Climate }\end{array}$ & $\begin{array}{l}\text { Vancouver, } \\
\text { British } \\
\text { Columbia }\end{array}$ & 29 & $\mathrm{D}$ \\
\hline 2 & $\begin{array}{l}\text { Colorado State } \\
\text { University }\end{array}$ & & $\begin{array}{l}\text { Ka-band Propagation Studies } \\
\text { Using ACTS Propagation } \\
\text { Terminal and the CSU- } \\
\text { CHILL Multiparameter, } \\
\text { Doppler Radar }\end{array}$ & $\begin{array}{l}\text { Fort Collins, } \\
\text { Colorado }\end{array}$ & 43 & $\mathrm{E}$ \\
\hline 3 & $\begin{array}{l}\text { University of } \\
\text { Alaska, } \\
\text { Fairbanks }\end{array}$ & & $\begin{array}{l}\text { ACTS Propagation } \\
\text { Measurements in Alaska }\end{array}$ & $\begin{array}{l}\text { Fairbanks, } \\
\text { Alaska }\end{array}$ & 8 & $\mathrm{C}$ \\
\hline 4 & $\begin{array}{l}\text { COMSAT } \\
\text { Laboratories }\end{array}$ & & $\begin{array}{l}\text { ACTS Uplink Transmit } \\
\text { Power Control Measurement } \\
\text { Experiment }\end{array}$ & $\begin{array}{l}\text { Clarksburg, } \\
\text { Maryland }\end{array}$ & 39 & $\mathrm{~K}$ \\
\hline 5 & $\begin{array}{l}\text { COMSAT } \\
\text { Laboratories }\end{array}$ & & $\begin{array}{l}\text { ACTS Propagation } \\
\text { Experiments }\end{array}$ & & & \\
\hline 6 & $\begin{array}{l}\text { Stanford } \\
\text { Telecommun- } \\
\text { ications, Inc. }\end{array}$ & $\begin{array}{l}\text { - New Mexico } \\
\text { State University } \\
\text { - NASA HQ } \\
\text { Code O } \\
\end{array}$ & $\begin{array}{l}\text { ACTS Propagation } \\
\text { Experiments }\end{array}$ & $\begin{array}{l}\text { Las Cruces, } \\
\text { New Mexico }\end{array}$ & 51 & $\mathrm{E}$ \\
\hline$\overline{7}$ & $\begin{array}{l}\text { University of } \\
\text { Oklahoma }\end{array}$ & & $\begin{array}{l}\text { Rain Attenuation Statistics for } \\
\text { the ACTS Propagation } \\
\text { Experiment for Central } \\
\text { Oklahoma }\end{array}$ & $\begin{array}{l}\text { Norman, } \\
\text { Oklahoma }\end{array}$ & 49 & M \\
\hline 8 & $\begin{array}{l}\text { 1. University of } \\
\text { South Florida } \\
\text { 2. Florida } \\
\text { Atlantic } \\
\text { University }\end{array}$ & & $\begin{array}{l}\text { Propagation Measurements } \\
\text { Using ACTS }\end{array}$ & $\begin{array}{l}\text { Tampa, } \\
\text { Florida }\end{array}$ & 52 & $\mathrm{~N}$ \\
\hline
\end{tabular}

participants, many of whom are contributors to this issue, can be found in [17].

The ACTS campaign is a continuation of an ongoing NASA propagation program managed from the Jet Propulsion Laboratory. A kick-off meeting of the ACTS campaign was held November 28-29, 1989, in Santa Monica, CA to identify general and ACTS-related propagation needs and to make recommendations (to NASA) for a study plan [18]. As a result, NASA released in December 1991 a NASA Research Announcement (NRA) titled "ACTS Propagation Experiments Implementation Program" to solicit interested participants. The intent was to have mostly universities involved that were located in those rain climatic zones where little previous propagation data were available [19].

\section{B. Class I Experiments}

The NRA was structured to obtain two general classes of experiments. The first class focused on making in situ measurements of the 20.2- and $27.5-\mathrm{GHz}$ beacons using NASA-provided, identical, receive-only terminals. Eight experiments were selected that involve seven geographic sites and nine organizations. This is summarized in Table 2. Comsat Laboratories was selected for two Class I experiments although it received only one propagation terminal.

The NASA-provided receive-only terminals were designed and built by the Virginia Polytechnic Institute and State University's Satellite Communications Group. The

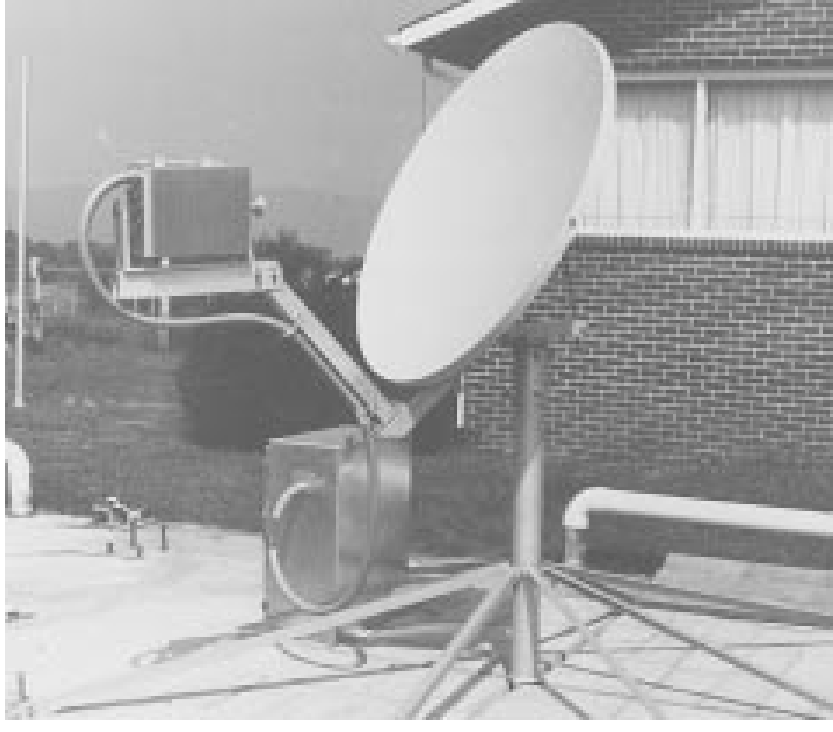

Fig. 5. ACTS 1.2-m receive-only propagation terminal.

reason for this was based on the university's experience from the European Olympus propagation program. The beacon receiver that the university developed for Olympus (12.5-, 19.8-, and 29.7-GHz coherent beacons) [20], [21] was the model for the ACTS propagation terminal [22]. The 1.2-m receive-only terminal is depicted in Fig. 5, while a link budget for its operation can be found in [23]. 
Table 3 ACTS Class II Propagation Experiments

\begin{tabular}{c|l|l|l|l}
\hline \hline$\#$ & $\begin{array}{l}\text { Principal } \\
\text { Investigator }\end{array}$ & $\begin{array}{l}\text { Co- } \\
\text { Investigator }\end{array}$ & \multicolumn{1}{|c|}{ Experiment Title } & Earth Station \\
\hline 1 & $\begin{array}{l}\text { 1. Johns Hopkins Univ., } \\
\text { Applied Physics } \\
\text { Laboratory } \\
2 . \text { Univ, of Texas, } \\
\text { Austin }\end{array}$ & $\begin{array}{l}\text { Land-Mobile-Satellite } \\
\text { Measurements in Central } \\
\text { Maryland and Alaska Using } \\
\text { ACTS: Passive Antenna } \\
\text { Tracking System and Mobile } \\
\text { Receiver System }\end{array}$ & $\begin{array}{l}\text { User-Provided } \\
\text { Mobile Receiver \& } \\
\text { NASA Link } \\
\text { Evaluation Terminal }\end{array}$ \\
\hline 2 & Comsat Laboratories & & $\begin{array}{l}\text { ACTS Wide Area Diversity } \\
\text { Experiment }\end{array}$ & $\begin{array}{l}\text { NASA TI VSAT \& } \\
\text { User-Provided } \\
\text { Receive-only } \\
\text { terminal }\end{array}$ \\
\hline 3 & $\begin{array}{l}\text { Georgia Tech Research } \\
\text { Corp. }\end{array}$ & Georgia Tech & $\begin{array}{l}\text { RF Propagation Effects and } \\
\text { ACTS Satellite Channel } \\
\text { Characterization for VSAT's }\end{array}$ & $\begin{array}{l}\text { Unique MSM-mode } \\
\text { terminal }\end{array}$ \\
\hline \hline
\end{tabular}

Detection of beacons was the first Ka-band signal received from ACTS on September 23, 1993, by the University of British Columbia at approximately 11:00 a.m. EST shortly after the beacons were activated. The spacecraft was still east of its station at $97.5^{\circ} \mathrm{W}$ longitude. It was agreed upon that official data collection from all sites would begin on December 1, 1993.

At the NASA Propagation Experimenters meeting (NAPEX XX) held in Fairbanks, AK, June 4-5, 1996, the first two complete years of analyzed data were presented from all seven sites [24]. A U.S. satellite industry ad hoc task team took the opportunity to take a critical look at the NASA propagation studies program at this meeting and recommended, among other things, that the ACTS propagation experiments should continue until a full five years of data are collected. NASA's ability to support this is, of course, dependent on the operational life of ACTS and available resources.

\section{Class II Experiments}

A second class of experiments was also selected, which involved using either the ACTS communications channels or the beacons. The goal was to investigate other aspects of radiowave propagation, such as multipath and blockage effects on mobile applications, delay spread, or alternative fade-mitigation techniques. These other experiments provided an opportunity to look into some of the other topics related to Ka-band propagation that are key to the successful operation of future applications in this band. Alternative or improved fade mitigation methods need to be thoroughly characterized for the low-margin systems planned, such as mobile and roaming terminals for personal communications systems. Improvements in frequency scaling models for techniques such as uplink power control and in understanding fade profiles and systems-networking handoffs for wide area diversity are also important. Investigating propagation effects of modulation schemes being considered for low uplink power systems such as code division multiplexing is also worthy.

The Class II experimenters were not provided one of the NASA receive-only terminals for these experiments by definition. Generally, the duration of the work was shorter than the Class I experiments. Results from these experiments are presented in other papers in this issue. The Class II experiments are summarized in Table 3. The first two experiments are completed [25], [26] and the third one is ongoing.

\section{CONCLUSION}

The ACTS propagation campaign began its planning over two-and-a-half years before the launch of the satellite. ACTS offered the only U.S. opportunity to perform Kaband propagation measurements using a domestic satellite. Workshops were held two times a year to organize the propagation program before launch and continue after launch to report progress and resolve problems. A NASA Research Announcement was issued to solicit experimenters. Seven Class I sites that operate identical ACTS propagation terminals are in locations where either insufficient or no data was available at Ka-band. By launch, all terminals were deployed and ready for data collection. The first Ka-band signals transmitted by the satellite were received first by one of the propagation terminals. Since December 1993, data have been collected and analyzed continuously and program operations are expected to continue at least through September 1997. A second group of experimenters, Class II, was selected to look at other Ka-band propagation issues, including mobile shadowing, wide area diversity, and propagation effects on VSAT systems.

Although the advanced technologies on ACTS include many firsts for U.S. satellite communications, characterizing the Ka-frequency band and its increased susceptibility to rain fades is critical for the commercial development of the next generation of satellites that plans to use these frequencies. The work done by all those involved has been slow, frustrating, and tedious at times. NASA is most grateful for all those that have worked to make this campaign successful throughout the difficult budget years, development and launch delays, and even government shutdowns. Their personal commitment and cleverness allowed them to make the best of what was available; their high work standards and ethic have led to a program with much to be proud of, and much work further to complete. 


\section{REFERENCES}

[1] "Project relay," NASA Facts G-12-62, U.S. Government Printing Office, Washington, D.C., 1963.

[2] "Space: The final frontier," NASA EP-6, U.S. Government Printing Office, Washington, D.C., p. 44, 1967.

[3] "Experiments planning document: $30 / 20 \mathrm{GHz}$ satellite communications project," NASA Lewis Research Center, Cleveland, OH, Doc. \#6200-2, June 1980.

[4] J. Rhea, "The satellite the White House hates," Space World, pp. 21-23, Aug. 1987.

[5] K. Herbst, "NASA to launch new era with switching satellite," Network World, p. 49, Apr. 17, 1989.

[6] F. Gargione, "The ACTS System," in Ka Band Utilization Conf., Rome, Italy, Oct. 1995, pp. 43-52.

[7] F. A. Regier, "The ACTS multibeam antenna," IEEE Trans. Microwave Theory Tech., vol. 40, pp. 1159-1164, June 1992.

[8] W. F. Cashman, "ACTS multibeam communications package: Description and performance characterization," in Proc. 14th Int. Communication Satellite Systems Conf. Exhibit, Washington, D.C., Mar. 1992, pp. 1151-1160.

[9] K. D. Lee, "Design and development of a baseband processor for the advanced communications technology satellite," presented at the ACTS Results Conf., Cleveland, OH, Sept. 1995.

[10] J. R. Manning, J. D. Spiegler, and P. A. Lowry, "ACTS T1-VSAT: The intelligent earth station," in Proc. 14th Int. Communication Satellite Systems Conf. Exhibit, Washington, D.C., Mar. 1992, pp. 1730-1737.

[11] L. C. Palmer, "Demand assignment in the ACTS LBR system," IEEE Trans. Commun., vol. 38, pp. 684-692, May 1990.

[12] S. J. Campanella, B. A. Pontano, and H. Chalmers, "Future switching satellites," in Proc. 12th Int. Communication Satellite Systems Conf., 1988, pp. 264-273.

[13] R. J. Schertler, "ACS experiments program," presented at the ACTS Results Conf., Cleveland, OH, Sept. 1995.

[14] P. Levine, "Supplementary description of ACTS beacon subcarrier spectra," GE Astro-Space Memo. NASA/ACTS-SE-242, Oct. 31, 1988.

[15] P. A. Lowry, "ACTS systems handbook," NASA Lewis Research Center, Cleveland, OH, Tech. Memo. TM-101490, pp. AB1-AB9, 1993.
[16] R. J. Krawczyk, "ACTS operational performance review-Sept. 1995," presented at the ACTS Results Conf., Cleveland, OH, Sept. 1995.

[17] F. Davarian, "Ka-band propagation measurements using ACTS," in Proc. Ka Band Utilization Conf., Rome, Italy, Oct. 1995, pp. 97-110.

[18] __ "Opening remarks," in Presentations 1st ACTS Propagation Studies Workshop (APSW I), Jet Propulsion Lab. Pub. JPL D-6918, Dec. 1989, pp. 4-6.

[19] "Advanced communications technology satellite propagation experiments implementation program," NASA Lewis Research Center, Cleveland, OH, NASA Research Announcement NRA 92-LeRC-1, Dec. 4, 1991.

[20] W. Stutzman, J. McKeeman, and T. Pratt, "Olympus propagation experiments," in Presentations 1st ACTS Propagation Studies Workshop (APSW I), Jet Propulsion Lab. Pub. JPL D6918, Dec. 1989, pp. 118-145.

[21] B. Arbesser-Rastburg, G. Brussard, and P. G. Davies, "Context of the Olympus Mission," in Proc. 2nd Workshop Olympus Experimenters, European Space Agency Doc. ESA WP-083, vol. 1, Nov. 1994, pp. 7-10.

[22] W. Stutzman, "ACTS propagation terminal update," in Presentations 4th ACTS Propagation Studies Workshop (APSW IV), Jet Propulsion Lab. Doc. D-10393, Jan. 1993, pp. 25-40.

[23] F. Davarian, "Ka-band propagation research using ACTS," Int J. Satellite Commun., vol. 14, no. 3, pp. 267-282, May-June 1996.

[24] N. Golshan, Ed., Proc. 20th NASA Propagation Experimenters Meeting (NAPEX XX) ACTS Propagation Studies Miniworkshop, Jet Propulsion Lab. Pub. 96-20, Sept. 1, 1996.

[25] J. Goldhirsh and W. J. Vogel, "An extended empirical roadside shadowing model for estimating fade distributions from UHF to K-band for mobile satellite communications," Space Commun., vol. 13 , no. 3, pp. 225-237, 1995.

[26] ACTS Wide Area Diversity Experiment, "Final report," Comsat Laboratories, SSTD/96-011, Mar. 1996.

Robert Bauer, for a photograph and biography, see this issue, p. 809 . 